\title{
Analisa Efektivitas Penerapan Jalur Khusus Sepeda Di Kota Palembang Pada Rute Jakabaring Sport City - BKB
}

\author{
Efrilia Rahamdona, Ricky Ravsyah Alhafez, Kiki Rizky Amalia \\ Jurusan Teknik Sipil, Politeknik Negeri Sriwijaya \\ Correspondence email: efriliarahmadona@polsri.ac.id
}

\begin{abstract}
Abstrak. Pemerintah kota Palembang telah meresmikan jalur khusus sepeda pada tahun 2020 lalu oleh Walikota Palembang, ada tiga rute resmi jalur khusus sepeda tersebut. Tiga jalur khusus pecinta sepeda ini dibuat pemerintah untuk menertibkan arus lalu lintas dan memfasilitasi para pengguna sepeda di kota Palembang. Dalam penerapan penggunaan jalur khusus sepeda pada kawasan kota Palembang masih mengalami kesulitan dikarenakan besarnya volume kendaraan pribadi yang di dominasi oleh kendaraan bermotor, selain itu masih minimnya pengguna sepeda dan tujuan bersepeda masih sebatas untuk olahraga. Tujuan penelitian adalah untuk menganalisis efektivitas jalur khusus sepeda di Kota Palembang menggunakan metode deskriptif kuantitatif dan metode analisis dengan teknik BLOS (Bicycle Level Of Service). Pengumpulan data dilakukan dengan survey. Hasil penelitian dan analisis dengan BLOS didapat hari Senin dan Minggu pada jam 06.00 - 08.00 WIB, 11.00 - 13.00 WIB, dan 16.00 - 18.00 WIB nilai BLOS berada pada peringkat "E" yaitu lebih dari 4,5 -5,5 artinya lingkungan tidak aman untuk sepeda.
\end{abstract}

Kata kunci: BLOS, efektivitas, jalur sepeda

\section{PENDAHULUAN}

Tren bersepeda di kota Palembang semakin meningkat selama pandemi covid-19, pemerintah kota mulai mendukung dengan menyediakan jalur khusus sepeda di kota Palembang. Berdasarkan UU Nomor 22 Tahun 2009 tentang Lalu Lintas dan Angkutan Jalan, tertulis mengenai jalur khusus sepeda dalam undang-undang tersebut menyatakan bahwa setiap jalan yang digunakan untuk lalu lintas umum wajib dilengkapi dengan perlengkapan jalan berupa fasilitas untuk sepeda, pejalan kaki, dan penyandang cacat (Pasal 25) dan fasilitas pendukung penyelenggaraan lalu lintas dan angkutan jalan meliputi lajur sepeda (Pasal 45) dan pemerintah harus memberikan kemudahan berlalu lintas bagi pesepeda, artinya para pesepeda berhak atas fasilitas pendukung keamanan, keselamatan, ketertiban dan kelancaran dalam berlalu lintas (Pasal 62). Pada tahun 2020 lalu Walikota Palembang meresmikan tiga rute jalur khusus sepeda di Kota Palembang. Tiga jalur khusus pecinta sepeda resmi dibuat pemerintah kota Palembang untuk menertibkan arus lalu lintas (Kompas, 2020). Apabila tidak ada upaya pengurangan volume kendaraan pribadi maka penerapan jalur khusus sepeda tidak akan berhasil (Artiningsih, 2011). Berdasarkan penelitian sebelumnya tujuan masyarakat bersepeda saat ini masih sebatas hanya sebagai sarana olahraga (Praditya,Norca, Rahmadona, Efrilia dkk, 2020), hal yang diharapkan kedepannya penggunaan sepeda bisa digunakan untuk kegiatan sehari-hari seperti bekerja dan sekolah bertujuan untuk mengurangi dominasi kendaraan pribadi, dilanjutkan dengan upaya meintegrasikan dengan transportasi publik yang telah tersedia seperti BRT dan LRT.

Penerapan penggunaan jalur khusus sepeda pada kawasan perkotaan Palembang masih mengalami kendala dikarenakan masih besarnya volume kendaraan pribadi yaitu kendaraan bermotor. Sementara itu penerapan jalur sepeda tidak akan berhasil apabila tanpa adanya upaya pengurangan volume kendaraan pribadi dan perbaikan fasilitas kendaraan tidak bermotor khususnya sepeda (Fadly, G., Widodo, S. dan Mayuni, S). Setelah pemerintah kota Palembang telah menyediakan jalur khusus sepeda untuk tiga rute jalur, diharapkan kedepannya di kota Palembang akan ditambah fasilitas pendukung lainnya untuk para pengguna sepeda, maka dari itu perlu diadakan kajian untuk mengetahui efektivitas penerapan jalur khusus sepeda yang telah ada, untuk mengetahui pengaruh kinerja jalur khusus sepeda terhadap lajur kendaraan bermotor dan tingkat efektivitas penerapan jalur khusus sepeda di kota Palembang agar Pemerintah Kota Palembang memiliki referensi untuk mengembangkan fasilitas pendukung lainnya.

\section{METODE}

Metode yang digunakan dalam penelitian ini adalah dengan cara survey volume lalu lintas pada jalan utama dan jalur sepeda, survey kecepatan kendaraan dan mengumpulkan data geometri jalan. Selanjutnya data-data tersebut diolah dan dianalisis dengan menggunakan metode Bicycle Level of Service (BLOS).

\section{Volume lalulintas}

Pengumpulan data volume lalu lintas dilakukan selama dua hari. Satu hari yang mewakili hari kerja (weekday) Senin dan satu hari mewakili hari libur (weekend) Minggu. Survey terdiri dari 3 sesi yaitu sesi pagi pada jam $06.00-$ 08.00 WIB, siang 11.00 -13.00 WIB dan malam 16.00 - 18.00 WIB. Rumus volume lalu lintas 
$\mathrm{q}=\mathrm{n} / \mathrm{t}$

Dimana :

$\mathrm{q} \quad=$ volume lalu lintas

$\mathrm{n} \quad=$ jumlah kendaraan

$\mathrm{t} \quad=$ interval waktu (jam, detik)

\section{Kecepatan kendaraan bermotor}

Rumus kecepatan kendaraan bermotor :

$\mathrm{v}=\mathrm{s} / \mathrm{t}$

Dimana :

$\mathrm{v}=$ kecepatan kendaraan $(\mathrm{km} / \mathrm{jam}, \mathrm{m} /$ detik $)$

$\mathrm{s} \quad=\operatorname{Jarak}(\mathrm{km}, \mathrm{m})$

$\mathrm{t} \quad=$ interval waktu (jam, detik)

Pada penelitian ini untuk menentukan kecepatan kendaraan menggunakan alat speed gun, dengan cara menembakkan langsung pada kendaraan yang lewat pada ruas jalan yang disurvey untuk selanjutnya dihitung kecepatan rata-rata kendaraan.

\section{Lebar Perkerasan}

Berikut Rumus lebar perkerasan lajur sepeda yaitu:

$\mathrm{Wt}=\mathrm{Wol}+\mathrm{Wbl}$

Dimana:

$\mathrm{Wt} \quad=$ Lebar total

Wol = Lebar lajur perjalanan

$\mathrm{Wbl}=$ Lebar lajur sepeda

Jenis Perkerasan Jalan Penentuan tingkat perkerasan ditentukan jenis perkerasan jalan sesuai standar FHWA.

\section{Kendaraan Berat}

Data kendaraan berat didapat dari survey lalulintas, analisa persentase kendaraan berat (PHva) di lakukan dengan membagi tiap kendaraan berat dengan jumlah arus lalu lintas kendaran per jam (Vma) lalu dikalikan dengan 100.

\section{Analisis Bicycle Level Of Service (BLOS)}

Data hasil survey selanjutnya diolah untuk mengetahui nilai tingkat pe;ayanan dan dianalis dengan metode Bicycle Level Of Service (BLOS). Rumus untuk menghitung tingkat pelayanan sepeda adalah sebagai berikut

$\mathrm{BLOS}=0,760+\mathrm{Fv}+\mathrm{Fs}+\mathrm{Fp}+\mathrm{Fw}$

Keterangan :

Konstanta $=0,760$

Faktor Volume $(\mathrm{Fv})=0,507 \ln (\mathrm{Vma} / 4 . \mathrm{Nth})$

$\mathrm{Vma}=$ Arus lalu lintas (kendaraan/jam)

Nth = Jumlah lajur dalam satu arah

$\mathrm{Wv}=\mathrm{Wt}$, Jika Vma $>160$ Kendaraan per jam.

Maka variabel ketika kondisi terpenuhi:

$\mathrm{Wt}=\mathrm{Wol}+\mathrm{Wbl}+$ Wos'

$\mathrm{We}=\mathrm{Wv}-10 \mathrm{Ppk}>0,00$

$\mathrm{Wv}=\mathrm{Wt}(2-0,00025 \mathrm{Vma})<160$

Kendaraan per jam, dan jika jalan/jalan tak penuh dan tak terbagi. Maka variabel ketika kondisi tidak terpenuhi:

$\mathrm{Wt}=\mathrm{Wol}+\mathrm{Wbl}$

$\mathrm{We}=\mathrm{Wv}+\mathrm{Wbl}+\mathrm{Wos}^{\prime}-20 \mathrm{Ppk}>0,00$ 
Keterangan

Ppk = Bagian parkir on-street dari lebar jalan

Wos = Lebar bahu yang diperkeras (parkir on-street)

Wos' = Lebar bahu yang diperkeras biasa (adjusted)

$\mathrm{Wbl}=$ Lebar lajur sepeda

Wol = Lebar lajur perjalanan

$\mathrm{Wt} \quad=$ Lebar total

$\mathrm{Wv} \quad=$ Lebar efektif

volume lalu lintas BLOS menggunakan enam rentang skala untuk mendeskripsikan kualitas segmen jalan untuk perjalanan sepeda mulai dari kondisi terbaik hingga terburuk berdasarkan persepsi pengguna.

\section{HASIL DAN PEMBAHASAN}

\section{Karakteristik Pengguna sepeda}

Hasil kuisioner dari 250 responden menunjukkan bahwa usia pengguna sepeda tertinggi pada rentang usia 36 45 tahun yaitu 40\%. Dalam intensitas penggunaan rute jalur sepeda yang tersedia sebanyak $78 \%$ responden menyatakan sering menggunakan jalur khusus sepeda dan alasan menggunakan sepeda yang paling mendominasi adalah untuk sarana olahraga sebanyak 84\% Data hasil kuisoner pada rute Jakabaring Sport City - BKB .

\section{Usia Pengguna Sepeda}

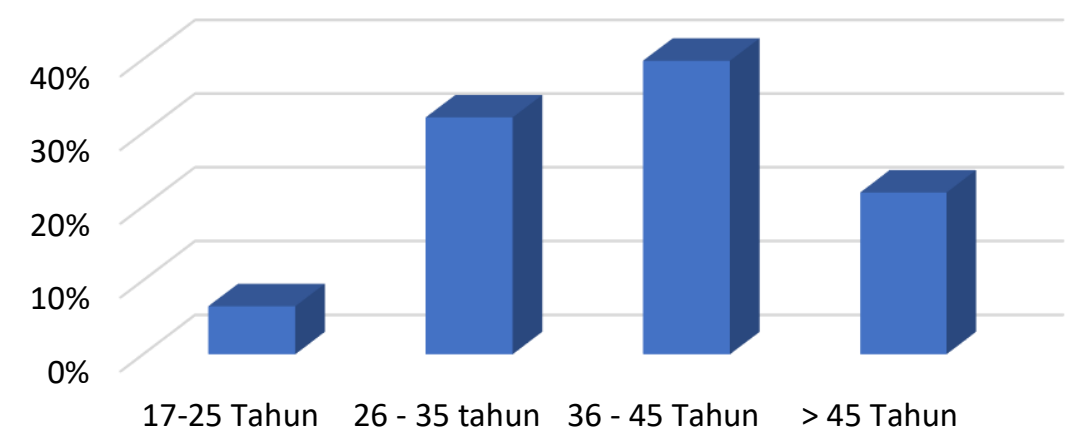

Gambar 1. Grafik Usia Pengguna Sepeda

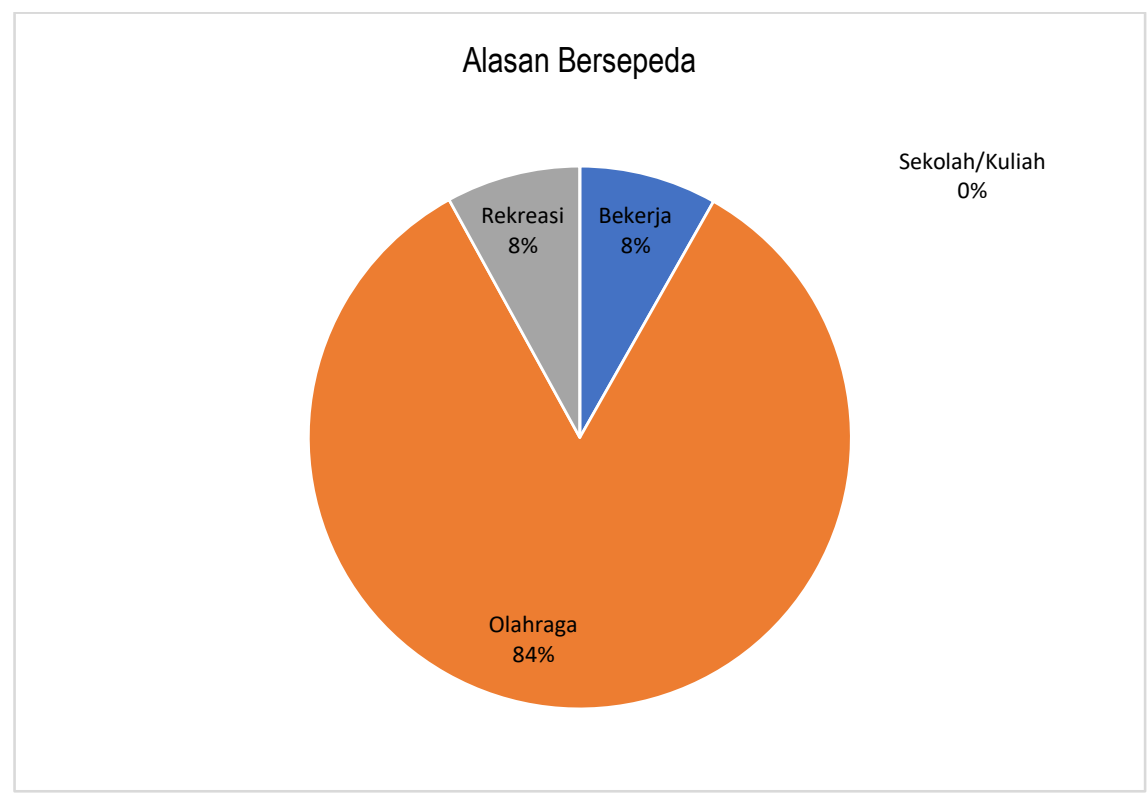

Gambar 2. Alasan bersepeda

\section{Tingkat Efektifitas Jalur Sepeda}

Perhitungan dimulai dengan menghitung jumlah arus kendaraan per jam (Vma), persentase kendaraan berat (PHva), kecepatan kendaraan bermotor (Sra), lebar efektif lajur luar (We) dan peringkat kondisi perkerasan (Pc). 
Volume lalu lintas (Vma) di sepanjang rute Jakabaring Sport City - Palembang BKB terpadat di Hari Senin berada pada jam 06.00-08.00 dengan jumlah 42.092 kendaraan/jam, pada hari minggu terpadat berada pada jam 06.00-08.00 dengan jumlah 38.502 kendaraan/jam. Kendaraan berat (Phva) pada rute Jakabaring Sport City - BKB (Tabel 2) pada Hari Senin yang terbanyak berada di jam 11.00-13.00 dengan persentase 0,59\%, pada hari minggu kendaraan berat yang terbanyak juga berada di jam 16.00-18.00 dengan jumlah 0,36\%.

Tabel 2. Persentase Kendaraan Berat

\begin{tabular}{|c|c|c|c|c|c|c|c|c|c|}
\hline Hari & $\begin{array}{l}\text { Jam } \\
(\text { WIB })\end{array}$ & $\begin{array}{l}\text { Bus } \\
\text { (unit) }\end{array}$ & $\begin{array}{l}\text { Vma (Jumlah } \\
\text { kendaraan/jam) }\end{array}$ & $\begin{array}{l}\text { Persen } \\
(\%)\end{array}$ & $\begin{array}{l}\text { Truk } \\
\text { (unit) }\end{array}$ & Ringan & $\begin{array}{l}\text { Vma (Jumlah } \\
\text { kendaraan / jam ) }\end{array}$ & $\begin{array}{l}\text { Persen } \\
(\%)\end{array}$ & $\begin{array}{l}\text { Kendaraan } \\
\text { Berat }(\%)\end{array}$ \\
\hline \multirow[t]{3}{*}{ Senin } & $06.00-08.00$ & 7 & 42092 & $0,02 \%$ & & 95 & 42092 & $0,23 \%$ & $0,24 \%$ \\
\hline & $11.00-13.00$ & 21 & 30051 & $0,07 \%$ & & 156 & 30051 & $0,52 \%$ & $0,59 \%$ \\
\hline & $16.00-18.00$ & 26 & 36418 & $0,07 \%$ & & 155 & 36418 & $0,43 \%$ & $0,50 \%$ \\
\hline \multirow[t]{3}{*}{ Minggu } & $06.00-08.00$ & 46 & 38502 & $0,12 \%$ & & 22 & 38502 & $0,06 \%$ & $0,18 \%$ \\
\hline & $11.00-13.00$ & 80 & 27961 & $0,29 \%$ & & 7 & 27961 & $0,03 \%$ & $0,31 \%$ \\
\hline & $16.00-18.00$ & 53 & 18705 & $0,28 \%$ & & 14 & 18705 & $0,07 \%$ & $0,36 \%$ \\
\hline
\end{tabular}

Sumber : Hasil perhitungan, 2021

Peringkat kondisi perkerasan (Pc) di Jalan sepanjang rute Jakabaring Sport City - BKB yaitu Jl. Gub. H. Bastari - Jl. Mayjend Ryacudu - Ampera - Jl. Merdeka - BKB (Gambar 3) sesuai Survey kondisi jalan bernilai 3 yang artinya kondisi perkerasan jalan cukup baik (sedang).

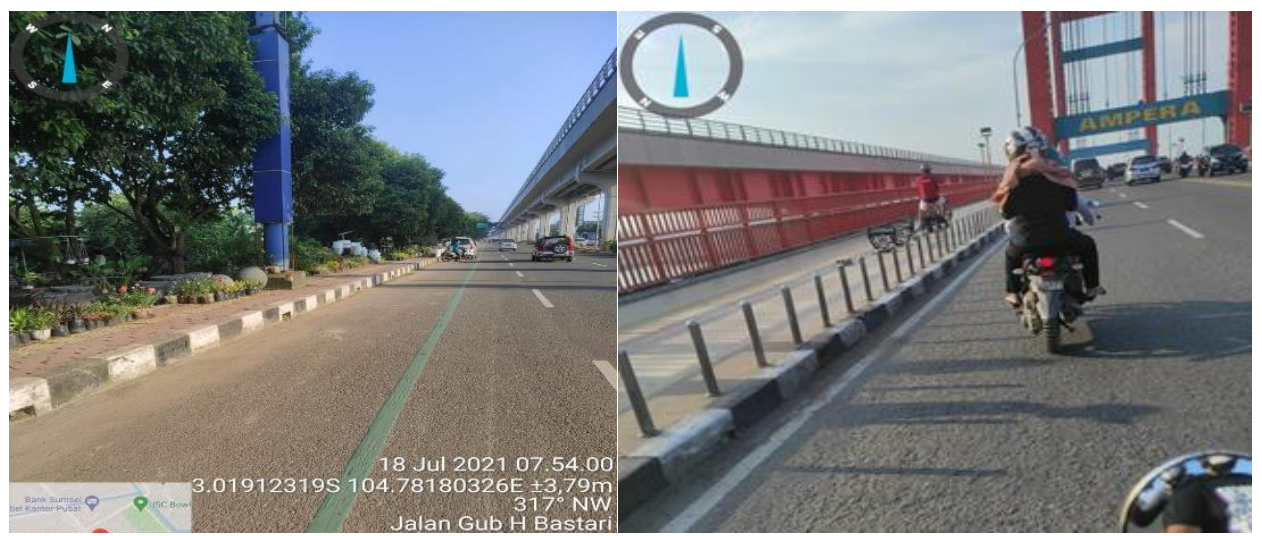

Gambar 3. Kondisi Perkerasan Jalan

Kecepatan Kendaraan (Sra) di Jalan sepanjang rute Jakabaring Sport City - BKB pada hari Senin, dan Minggu (Tabel 3). Kecepatan kendaraan pada hari Senin yaitu mobil sebesar $32 \mathrm{~km} / \mathrm{jam}$, sepeda motor sebesar $32 \mathrm{~km} / \mathrm{jam}$ dan sepeda $16 \mathrm{~km} / \mathrm{jam}$ dengan jam puncak arus kendaraan paling tinggi berada pada jam 06.00-08.00 dengan jumlah 42.092 jumlah kendaraan/jam. Sedangkan Kecepatan kendaraan pada hari Minggu yaitu sepeda motor sebesar 32 $\mathrm{km} / \mathrm{jam}$, mobil sebesar $32 \mathrm{~km} / \mathrm{jam}$, dan sepeda $16 \mathrm{~km} / \mathrm{jam}$ dengan jam puncak arus kendaraan paling tinggi berada pada jam 06.00-08.00 dengan jumlah 38.502 jumlah kendaraan/jam.

Tabel 3. Kecepatan Kendaraan ( $\mathrm{km} / \mathrm{jam})$

\begin{tabular}{ccccc}
\hline \multirow{2}{*}{ Hari } & \multirow{2}{*}{ Jam } & \multicolumn{3}{c}{ Kecepatan Kendaraan $(\mathrm{km} / \mathrm{jam})$} \\
\cline { 3 - 5 } Senin & $06.00-08.00$ & 32 & 33 & 16 \\
& $11.00-13.00$ & 26 & 27 & 16 \\
& $16.00-18.00$ & 32 & 34 & 16 \\
\multirow{3}{*}{ Minggu } & $06.00-08.00$ & 32 & 33 & 16 \\
& $11.00-13.00$ & 26 & 27 & 16 \\
& $16.00-18.00$ & 32 & 34 & 16 \\
\hline
\end{tabular}

Sumber: Hasil perhitungan, 2021

Jumlah lajur (Nth) rata-rata di jalan rute Jakabaring Sport City - BKB adalah 4 lajur. Lebar lajur sepeda (Wbl) adalah $1,5 \mathrm{~m}$ dan lebar lajur perjalanan (Wol) adalah $8 \mathrm{~m}$. Lebar jalan parkir on street (PPK), Lebar bahu yang diperkeras parkir on street (Wos) dan lebar bahu yang diperkeras biasa (Wos') di Jalan rute Jakabaring Sport City BKB tidak ada. Hasil perhitungan kondisi eksisting Jalan dapat dilihat pada Tabel 4. 
Efrilia Rahamdona et al., Analisa Efektivitas Penerapan Jalur Khusus Sepeda Di Kota Palembang Pada Rute Jakabaring Sport City $-B K B$

Tabel 4. Kondisi Eksisting Jalan

\begin{tabular}{cccccccccccc}
\hline Hari & Jam (WIB) & Vma & Phva & Pc & Sra & Nth & Ppk & Wos & Wos' & Wbl & Wol \\
\hline Senin & $06.00-08.00$ & 42092 & $0,24 \%$ & 2 & 32 & 4 & 0 & 0 & 2 & 1,5 & 10 \\
& $11.00-13.00$ & 30051 & $0,59 \%$ & 2 & 26 & 4 & 0 & 0 & 2 & 1,5 & 10 \\
& $16.00-18.00$ & 36418 & $0,50 \%$ & 2 & 32 & 4 & 0 & 0 & 2 & 1,5 & 10 \\
Minggu & $06.00-08.00$ & 38502 & $0,18 \%$ & 2 & 32 & 4 & 0 & 0 & 2 & 1,5 & 10 \\
& $11.00-13.00$ & 27961 & $0,31 \%$ & 2 & 26 & 4 & 0 & 0 & 2 & 1,5 & 10 \\
& $16.00-18.00$ & 18705 & $0,36 \%$ & 2 & 32 & 4 & 0 & 0 & 2 & 1,5 & 10
\end{tabular}

Sumber : Hasil perhitungan, 2021

Keterangan :

Vma = Jumlah Arus Kendaraan (Jumlah kendaraan/jam)

PHva = Persentase kendaraan berat $(\%)$

$\mathrm{Pc} \quad=$ Peringkat kondisi perkerasan

Sra = Kecepatan kendaraan bermotor $(\mathrm{Km} / \mathrm{jam})$

Nth = Jumlah lajur dalam satu arah perjalanan (Lajur)

PPK = Bagian parkir on-street lebar jalan

Wos = Lebar bahu yang diperkeras (parkir on-street)

Wos' = Lebar bahu yang diperkeras biasa (adjusted)

$\mathrm{Wbl}=$ Lebar lajur sepeda

Wol = Lebar lajur perjalanan

Berdasarkan hasil analisis dengan metode Bicycle Level Of Service (BLOS) pada rute Jakabaring Sport City BKB Kota Palembang pada hari Senin dan Minggu (Tabel 5), nilai BLOS pada hari weekday, Senin peringkat BLOS pada jam 06.00-08.00 WIB, 11.00 -13.00 WIB, 16.00 -18.00 WIB adalah "E" nilai lebih dari 4,5 artinya lingkungan sangat kurang untuk sepeda (tidak cocok untuk pesepeda apapun). dan pada hari Minggu peringkat "E" terjadi pada jam, 06.00-08.00 WIB, 11.00-13.00 WIB, 16.00 -18.00 WIB, karena padatnya jumlah kendaraan sehingga pengguna sepeda kurang nyaman dalam bersepeda di sepanjang rute Jakabaring Sport City - BKB yang disebabkan besarnya volume kendaraan bermotor yang di dominasi oleh kendaraan pribadi. Prioritas utama dalam penanganan jalur sepeda adalah faktor kenyamanan dan faktor keselamatan bagi pengguna sepeda. Kendaraan bermotor masih mendominasi sehingga penerapan penggunaan jalur sepeda masih mengalami kesulitan, tentunya penerapan lajur sepeda tidak akan berhasil tanpa upaya pengurangan volume kendaraan bermotor pribadi itu sendiri.

Tabel 5. BLOS

\begin{tabular}{ccccccccc}
\hline \multirow{2}{*}{ Hari } & \multirow{2}{*}{ Jam } & \multirow{2}{*}{ Konstanta } & \multirow{2}{*}{ Fv } & Fs & Fp & \multirow{2}{*}{ Fw } & \multicolumn{2}{c}{ Peringkat Nilai } \\
\cline { 4 - 9 } & & & & & & & Angka & Huruf \\
\cline { 2 - 9 } Senin & $06.00-08.00$ & 0,76 & 2,54 & 0,62 & 1,77 & $-0,91$ & 4,77 & $\mathrm{E}$ \\
\cline { 2 - 9 } & $11.00-13.00$ & 0,76 & 2,54 & 0,40 & 1,77 & $-0,91$ & 4,55 & $\mathrm{E}$ \\
\hline \multirow{3}{*}{ Minggu } & $16.00-18.00$ & 0,76 & 2,54 & 0,62 & 1,77 & $-0,91$ & 4,77 & $\mathrm{E}$ \\
\cline { 2 - 9 } & $06.00-08.00$ & 0,76 & 2,54 & 0,61 & 1,77 & $-0,91$ & 4,76 & $\mathrm{E}$ \\
\cline { 2 - 9 } & $11.00-13.00$ & 0,76 & 2,54 & 0,39 & 1,77 & $-0,91$ & 4,54 & $\mathrm{E}$ \\
\hline
\end{tabular}

Sumber : Hasil perhitungan, 2021

\section{SIMPULAN}

1. Berdasarkan dari hasil perhitungan dan analisis efektifitas tingkat pelayanan jalur sepeda di kota Palembang, khususnya rute Jakabaring Sport City - BKB dengan menggunkan metode BLOS (Bicycle Level Of Service) diketahui bahwa nilai BLOS pada hari Senin rata-rata lebih dari 4,5 -5,5 artinya lingkungan tidak aman untuk sepeda, hal tersebut dikarenakan pada hari weekday, volume lalulintas masih tinggi oleh kendaraan bermotor, khususnya didominasi oleh kendaraan pribadi. Sedangkan pada hari Minggu pada pukul $06.00-08.00$ dan $11.00-$ 13.00 dan 16.00 -18.00 nilai BLOS juga berada pada rentang 4,5 - 5,5.

2. Jumlah arus lalulintas di kota Palembang, khususnya pada rute Jakabaring Sport City - BKB termasuk tinggi, sehingga lingkungan masih belum bisa membuat para pesepeda nyaman dana man. Diharapkan Pemerintah kota Palembang tidak hanya menyediakan rute jalur sepeda tetapi juga memperhatikan segi kenyamanan dalam berkendaraan non bermotor dengan mengembangkan sarana dan prasarana pendukung jalur sepeda,berintegrasi dengan transportas publik dan penerapan transportasi publik yang memadai dan mengurangi penggunaan kendaraan pribadi. 


\section{DAFTAR PUSTAKA}

Artiningsih, M. Muktial, R. Kirana, and R. Kusumaningrum, "Kajian peluang penerapan jalur khusus sepeda di kota padang," Riptek, vol. 5, no. November 2011, pp. 1-7, 2018.

UU No. 22 Tahun 2009, “UU no.22 tahun 2009.pdf.” p. 203, 2009.

N. Praditya, E. Rahmadona, S. Sudarmadji, and A. S. Pratama, "Karakteristik Pengguna Sepeda Lipat Terhadap Pemilihan Moda Transportasi Di Kota Palembang," Bear. J. Penelit. dan Kaji. Tek. Sipil, vol. 6, no. 4, pp. 218 225, 2021, doi: 10.32502/jbearing.3216202064.

G. Fadly, S. Widodo, and S. Mayuni, “Analisis Efektivitas Lajur Khusus Sepeda pada Kawasan Perkotaan Pontianak Studi Kasus ( Jalan Gusti Sulung Lelanang - Kh. Ahmad Dahlan - Johar - Hos Cokroaminoto),” J. PWK, Laut, Sipil, Tambang, vol. 7, no. 1, pp. 1-8, 2020.

D. Sulistyo, B. Triana, and N. Winarsih, "Upaya Penggunaan Sepeda Sebagai Moda Transportasi Di Kota Surabaya," Proceeding PESAT (Psikologi, Ekon. Sastra, Arsit. \&Sipil), vol. 4, pp. 46-50, 2011.

S. Ayu Iskandar et al., "Ge-STRAM: Jurnal Perencanaan dan Rekayasa Sipil Analisis Efektifitas Jalur Sepeda Berdasarkan Metode Bicycle Level Of Service (BLOS)."

H. H. Sugasta, S. Widodo, and S. Mayuni, "Analisis Efektivitas Lajur Khusus Sepeda Pada Kawasan Perkotaan Pontianak ( Studi Kasus Jalan Sutan Syahrir - Jalan Jendral Urip - Jalan K. H. W. Hasyim - Jalan Merdeka),” J. Rekayasa Sipil, vol. 4, no. 4, pp. 1-9, 2016, [Online]. Available: http://jurnal.untan.ac.id/index.php/JMHMS/article/view/19197. 